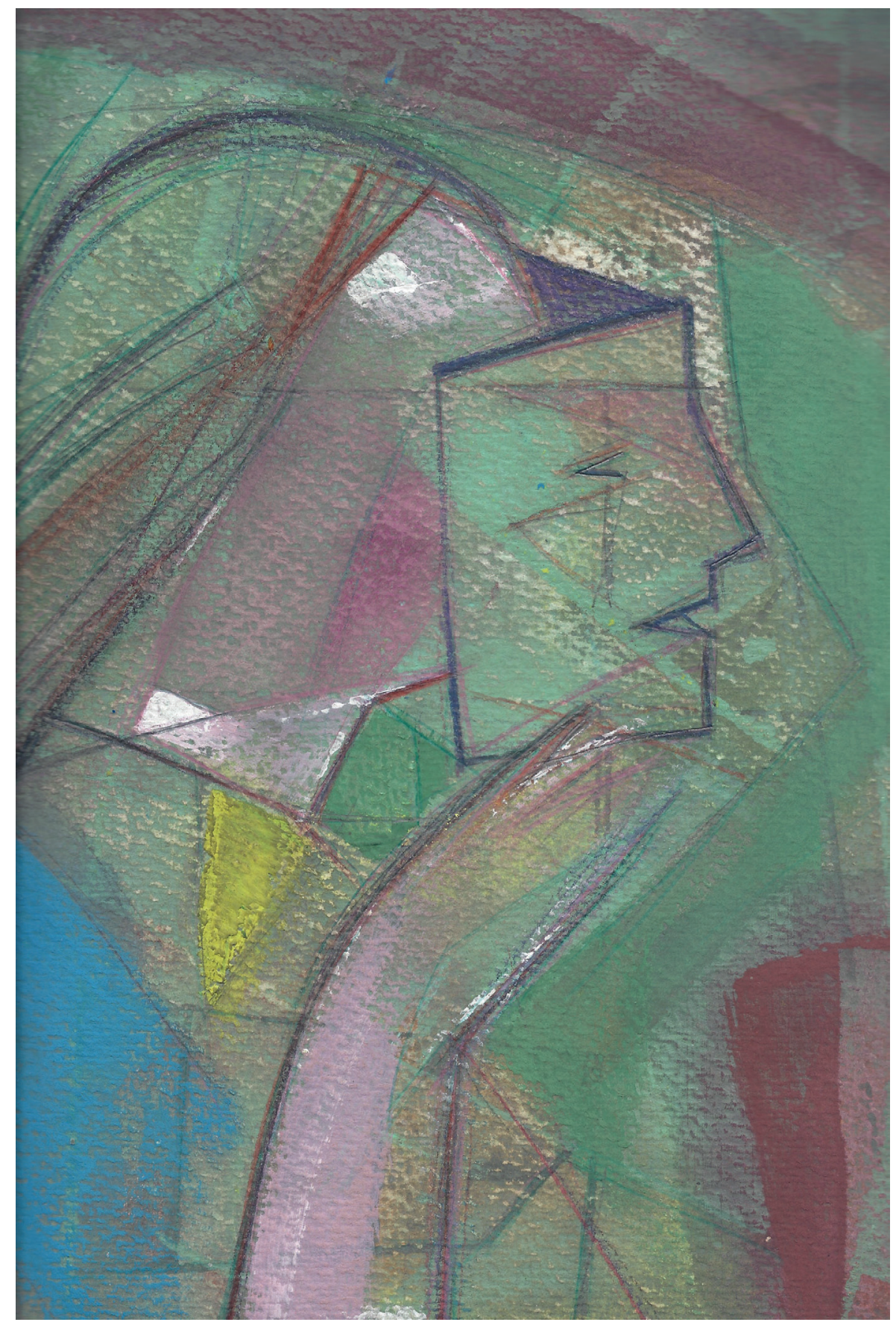


AUTOR: Javier Cabo 


\title{
Análise imagolóxica do discurso narrativo do personaxe cadalsiano Gazel en Cartas marruecas
}

\author{
Laura Caamaño Pérez \\ [Recibido, 5 marzo 2019; aceptado, 10 xuño 2019] \\ http://dx.doi.org/10.15304/bgl.54.5873
}

RESUMO Ofrécese, partindo dos estudos literarios comparados e centrándonos na análise imagolóxica, unha reflexión sobre o discurso narrativo do personaxe Gazel Ben-Aly, un dos protagonistas de Cartas marruecas, da autoría de José Cadalso, por considerar que se trata dunha das obras literarias máis relevantes da llustración española.

PALABRAS-CHAVE: Cartas marruecas; Imagoloxía; Gazel Ben-Aly.

ABSTRACT It is offered, based on the comparative literary studies and focusing on the imagological analysis, a reflection about the narrative discourse of Gazel Ben-Aly character, one of the protagonist of Cartas marruecas, written by José Cadalso, since it is considered as a literary masterpiece of Spanish Enlightenment. KEYwORDS: Cartas marruecas; Imagology; Gazel Ben-Aly.

El análisis y estudio de las imágenes mediante las que expresamos y configuramos nuestra idea de los otros, del "Otro", nos ayuda a vernos y definirnos a nosotros mismos (GARCía GUAL, 1995: 191).

\section{Introdución}

O conxunto de epístolas que conforma a obra literaria Cartas marruecas (1789), de José Cadalso (Cádiz, 1741-1782), sen dúbida, caracterízase polas posibilidades que ofrece para realizar unha análise comparatista, pois, como xa se anuncia dende o propio título e consta na "Introdución", as misivas son "Cartas escritas por un moro llamado Gazel Ben-Aly a Ben-Beley, amigo 
suyo, sobre los usos y costumbres de los españoles antiguos y modernos, con algunas respuestas de Ben-Beley, y otras cartas relativas a éstas" (Cadalso, 1997: 78). Este paratexto revela a intención clara do autor: criticar a cultura propia dende o punto de vista do "Outro". Como xa sinalou Fabbri (2002: 135), "Cadalso se presenta como atento observador de las costumbres españolas y agudo crítico de comportamientos, tendencias y modas”. Así, o escritor válese dun personaxe ficticio como é Gazel, un adolescente de orixe marroquí, para realizar unha comparación entre o país de orixe do personaxe e o país visitado, neste caso, España.

A publicación de Cartas marruecas en 1789 aparece nun contexto de eclosión intelectual e cultural cun claro afán reformista. Déixase atrás, polo tanto, unha literatura barroca, baseada no enxeño, no cultismo e no conceptualismo, para dar paso a unha época onde predominaba a razón, coa que se pretendía combater a ignorancia do país. Este novo movemento cultural e intelectual coñécese como Ilustración e nel destacan un conxunto de intelectuais (nobres, burgueses e clérigos) defensores da necesidade de reformar o país a través da razón. É aquí onde se encadra Cartas marruecas, obra dividida en noventa misivas nas que o autor "advierte claramente la amplitud y profundidad de la decadencia española, política, económica, social y cultural al mismo tiempo" (Fabbri, 2002: 133).

\section{Análise imagolóxica en Cartas marruecas a partir do personaxe Gazel}

O personaxe Gazel Ben-Aly é, sen dúbida, un dos máis representativos da obra con características peculiares e determinantes. A elección por parte do autor deste personaxe, polo tanto, non foi casual. Gazel é un adolescente africano, de orixe marroquí e de relixión musulmá, que chega a España co propósito de "viaxar con utilidade", isto é, coñecer os usos e costumes do territorio hispano para logo comparalos cos seus. Este era un dos obxectivos dos ilustrados na época: a tarefa de viaxar non consistiría nunha actividade puramente pracenteira e de goce senón que se trataba dunha experiencia na cal o viaxeiro debía preocuparse por coñecer os cidadáns, os costumes e a súa realidade social e política, de aí o afán de viaxar "con utilidade": 
Mi ánimo era viajar con utilidad, y este objeto no puede siempre lograrse en la comitiva de los grandes señores, particularmente asiáticos y africanos. Éstos no ven, digámoslo así, sino la superficie de la tierra por donde pasan; su fausto, los ningunos antecedentes por dónde indagar las cosas dignas de conocerse, el número de sus criados [...] (Cadalso, 1997: 83).

O relato focalízase na figura deste personaxe, que desenvolve a función de narrador en primeira persoa. Durante a súa estadía no país alleo, neste caso, en España, o personaxe percorre espazos afastados da súa experiencia propia e accede deste xeito ao coñecemento do "Outro". Unha vez no territorio estranxeiro, intenta adherirse á nova cultura, adquirindo usos e costumes propios do país que visita: "me hallo vestido como estos cristianos, introducido en muchas de sus casas, poseyendo su idioma, y en amistad muy estrecha con un cristiano llamado Nuño Núñez [...]" (Cadalso, 1997: 83).

Como queda claro nesta carta II, Gazel non se distancia da comunidade nova, senón que intenta introducirse nela para aprender e sacarlle o máximo proveito á súa viaxe. Aparece, polo tanto, seguindo a Álvaro Manuel Machado e Daniel-Henry Pageaux (1988), unha das actitudes básicas de achegamento ao "Outro" a través da "filia". Deste xeito, Gazel considera a nova cultura como algo positivo, mesmo considera que podería aprender dela.

Cunha clara intención comparatista, Gazel afirma que vai contemplar a realidade na que está inserido da maneira máis obxectiva posíbel, tendo especial coidado de non caer en caracterizacións simplificadas e convencionais do que está a ver ou, o que é o mesmo, tentando afastarse de estereotipos (Equipo Glifo, 1998: 246-247).

Observaré las costumbres de este pueblo, notando las que le son comunes con las de otros países de Europa, y las que le son peculiares. Procuraré despojarme de muchas preocupaciones que tenemos los moros contra los cristianos, y particularmente contra los españoles. Notaré todo lo que me sorprenda [...] (Cadalso, 1997: 83-84).

Pola súa parte, Homi K. Bhabha (2002), para explicar a noción de estereotipo, recorre ao "fetiche" de Freud, relacionando o estraño (sexual ou racial) co familiar (fetiche ou estereotipo). Este estereotipo funciona, polo tanto, como substituto do suxeito colonial cuns atributos característicos. A mirada inxenua de Gazel, semellante á dun neno que comeza a ver a realidade 
por vez primeira, favorece a creación dunha imaxe do "Outro" sen prexuízos, adoptando unha postura relativamente obxectiva do que está vendo. Isto será clave á hora de estabelecer comparacións entre o país de orixe e o estranxeiro. Con todo, o contacto estreito e directo co lugar observado provoca en Gazel mudanzas á hora de opinar sobre o territorio visitado. Polo tanto, esa mirada inocente e obxectiva, que tiña ao pouco tempo de chegar, cambia. Gazel comeza a sinalar o que lle parece negativo e xorde a manía. A mirada positiva inicial convértese en negativa, sinalando os usos non compartidos. Nalgunhas ocasións, Gazel amosa esa actitude crítica cara á moitas das prácticas e dos costumes da sociedade española, o que fai que chegue a rexeitar e desbotar certos modos de comportamento que non comparte.

Bos exemplos do comentado son as manifestacións que se reflicten na carta $\mathrm{X}$ onde se pode ver un Gazel contrario e moi crítico coa práctica da poligamia. Gazel ve na conduta dos españois un trato vexatorio e machista cara ás mulleres, carentes de valor e tratadas como meros obxectos sexuais. A través da ironía, Cadalso censura esta práctica e critica, de novo, a sociedade española da época:

Ahora, amigo Ben-Beley, 18 mujeres por día en los 365 del año de estos cristianos, son 6.570 conquistas las de este Hernán Cortés del género femenino; y contando con que este héroe gaste solamente dende los 17 años de su edad hasta los 33 en semejantes hazañas, tenemos que asciende el total de sus prisioneras en los 17 años útiles de su vida a la suma y cantidad de 111.690 [...] (Cadalso, 1997: 121).

Unhas cartas máis adiante, en concreto, na carta XVIII, Gazel dirixíndose ao seu eloxiado Ben-Beley, cuestiona o tema das relacións paterno-filiais, subliñando a nefasta relación existente entre pais e fillos e viceversa. Esta cuestión causa gran desconcerto e estrañeza no viaxeiro. Así, en palabras do propio Gazel:

Dende la primera vez que desembarqué en Europa, no he observado cosa que me haya sorprendido como la que voy a participar en esta carta. Todos los sucesos políticos de esta parte del mundo, por extraordinarios que sean, me parecen más fáciles de explicar que la frecuencia de pleitos entre parientes cercanos, y aun entre hijos y padres (Cadalso, 1997: 135).

De feito, é tal o desconcerto que non é capaz de entender o motivo polo que pode chegar a suceder isto. Atopámonos, unha vez máis, ante unha rea- 
lidade que é rexeitada polo "Outro", que configura así unha visión negativa da comunidade observada, considerándoo como un "vicio" máis da sociedade española:

Este vicio europeo no llevaré yo a África. Me tuviera por más delincuente que si llevara a mi patria la peste de Turquía [...]. ¡Qué mofa harían de mí los jóvenes europeos si cayesen en sus manos impías estos renglones! ¡Cuánta necedad brotaría de sus insolentes labios! ¡Cuán ridículo objeto sería yo a sus ojos! Pero aun así, despreciaría al escarnio de los malvados, y me apartaría de ellos por mantener mi alma tan blanca como la leche de las ovejas (Cadalso, 1997: 136).

Se ben até o momento o personaxe de Gazel falaba da sociedade española en termos xerais, na carta XXVI, elabora unha detallada descrición de boa parte das comunidades que conforman España. Nela, son evidentes os prexuízos e estereotipos que se teñen de cada pobo, caricaturizando as diferentes rexións. Así, comeza caracterizando os cántabros, dos cales di que "son pueblos sencillos [...], y han mantenido siempre la fama de excelentes hombres de mar" (Cadalso, 1997: 148). No que fai ao paisaxe asturiano, opina "que sus montañas hacen sumo aprecio de su genealogía, [...]" (Cadalso, 1997: 148). Logo, cuestiona o territorio galego, dicindo dos seus habitantes que "son excelentes para la infantería por su subordinación, dureza de cuerpo y hábito de sufrir incomodidades de hambre, sed y cansancio" (Cadalso, 1997: 149). En canto aos casteláns de Castela, segundo el, "son, de todos los pueblos del mundo, los que merecen la primacía en línea de lealtad" (Cadalso, 1997: 149). Extremadura é o territorio que "produjo los conquistadores del nuevo mundo [...]. Sus padres son poco afectos a las letras; pero los que entre ellos las han cultivado no han tenido menos suceso que sus patriotas en las armas" (Cadalso, 1997: 150). En canto aos andaluces, Gazel considera que "tienen fama de ser algo arrogantes" (Cadalso, 1997: 150). De Murcia afirma que "los murcianos participan del carácter de los andaluces y valencianos" (Cadalso, 1997: 150). Os cataláns son presentados como "los pueblos más industriosos de España" (Cadalso, 1997: 151) e, por último, comenta que os aragoneses "son hombres de valor y espíritu, honrados, tenaces en su dictamen, amantes de su provincia y notablemente preocupados a favor de sus paisanos" (Cadalso, 1997: 151).

Nas cartas XXXVIII e LVI, Gazel identifica máis comportamentos non compartidos do país visitado, como ser, o feito de ser profundamente orgullosos e soberbios, destacando o carácter frívolo e banal das xuntanzas propias 
da época. Deste xeito, a través do personaxe de Gazel, Cadalseo fai unha crítica á nobreza, considerándoa superficial e carente de valores. $\mathrm{O}$ autor xoga coa comicidade para censurar a futilidade dalgúns círculos sociais. A carta LXXII é outro exemplo desa censura á cultura allea. Neste caso, abórdanse as corridas de touros. Unha vez máis, Gazel rexeita esta práctica habitual en España:

ya no me parecen extrañas las mortandades que sus historias dicen de abuelos nuestros en la batalla de Clavijo, Salado, Navas y otras, si las excitaron hombres ajenos $[. .$.$] que pagan dinero por ver derramar sangre, teniendo esto por diver-$ sión dignísima de los primeros nobles (Cadalso, 1997: 257).

Con todo, a visión pesimista que ten Gazel de España compleméntase cunha experiencia positiva e mesmo enriquecedora para el. O automóbil de Gazel avaríase (a causa do deterioro das autoestradas españolas) e, grazas a isto, coñece un home que lle chama moito a atención. Este personaxe desempeña a función de "home de ben", é dicir, de home instruído que pode axudar á sociedade a saír da crise. Polo tanto, é un home xeneroso e preocupado pola familia e, por conseguinte, digno de ser aceptado e admirado polo "Outro". Cadalso aproveita este personaxe para demostrar o que, segundo el, debe ser un cidadán exemplar, un modelo a seguir polo resto dos españois.

A carta XX, malia estar escrita por Ben-Beley e dirixida a Nuño Núñez, resulta sumamente interesante pois nela o personaxe amósase contrariado ante a realidade descrita polo seu discípulo Gazel quen, ao ser a primeira vez que desenvolve a función de espectador, podería caer en erros e, por conseguinte, realizar unha incorrecta interpretación da realidade que ve:

dime, Nuño, ¿son verdaderas muchas de las noticias que me envía sobre las costumbres y usos de tus paisanos? Suspendo el juicio hasta ver tu respuesta. Algunas cosas me escribe incompatibles entre sí. Me temo que su juventud le engañe en algunas ocasiones y me represente las cosas no como son, sino cuales se le representaron (Cadalso, 1997: 138).

Como se pode observar ao final deste fragmento, a Ben-Beley cústalle crer que España sexa como Gazel a describe nas súas epístolas: "sus cartas, que copio con exactitud y suelo leer con frecuencia, me representan tu nación diferente de todas en no tener carácter propio, que es el peor carácter que puede tener" (Cadalso 1997: 138). Na derradeira misiva, a número XC, Gazel avisa o seu amigo Nuño de que abandona España para volver a Marrocos, 
lamentándose por non poder quedar máis tempo no país: "siento dejar tan pronto tu tierra y tu trato. Ambos habían empezado a inspirarme ciertas ideas nuevas para mí hasta ahora, de las cuales me había privado mi nacimiento y educación [...]" (Cadalso, 1997: 300).

\section{Conclusións}

A modo de conclusión é de destacar que José Cadalso agóchase a el mesmo detrás desa visión do "Outro", aínda que recorra ao personaxe de Gazel por identificalo co homo viator de Pageaux (1985), ese viaxeiro que adopta o papel de comparatista entre culturas diferentes,. Por iso, emprega o personaxe de Gazel cunhas características moi concretas e determinadas. Coloca o foco sobre un adolescente marroquí, de relixión musulmá, afastado da cultura española, o que lle permite con máis verosimilitude levar a cabo unha profunda crítica da propia cultura.

Todo o comentado vese reforzado tamén coa visión doutros dous personaxes máis: Ben-Beley, un musulmán que nunca visitou España, e Nuño Núñez, un cristián que vive dentro do país. Deste xeito, a través da ironía e a comicidade, créase a imaxe da propia nación, pois, como sinala Fabbri (2002: 131), "mediante Ben-Beley, Gazel, Nuño, Cadalso expresa juicios y opiniones comunes sobre los mayores problemas de su tiempo".

Laura Caamaño Pérez Centro Ramón Piñeiro para a Investigación en Humanidades

\section{Bibliografía}

Bhabha, Homi K. 2002. El lugar de la cultura. Buenos Aires: Manantial.

Cadalso, José. 1997. Cartas marruecas; Noches lúgubres. Madrid: Cátedra.

Equipo Glifo. 1998. Dicionario de termos literarios (e-b). Santiago de Compostela: Xunta de Galicia/Centro Ramón Piñeiro para a Investigación en Humanidades. http://www.cirp.gal/pls/bal2/f?.p=106:2:9983663307039922680::NO:2:P2_ TERMO :estereotipo [Consulta 25/02/2019]

Fabbri, Maurizio. 2002. "Don José Cadalso relator de las Cartas marruecas", en http:// www.cervantesvirtual.com/nd/ark:/59851/bmcgm855 [Consulta 26/02/2019]. 
García Gual, Carlos. 1995. "Mitocrítica, temática, imagología", en Thélème, nº 7, pp. 187-192. http://revistas.ucm.es/index.php/THEL/article/view/THEL9595230187A/34135 [Consulta 12/02/2019].

Machado, Álvaro Manuel e Pageaux, Daniel-Henri. 1988. Da literatura comparada à teoría da literatura. Lisboa: Ediçoes 70.

Pageaux, Daniel-Henri. 1985. "Le comparatiste: homo viator", en Neohelicon, no 12, pp. 201-211. DOI https://doi.org/10.1007/BF02092953 